\title{
Conditional value-at-risk for water management in Lake Burley Griffin
}

\author{
R. B. Webby* J. Boland ${ }^{\dagger} \quad$ P. G. Howlett ${ }^{\dagger}$ \\ A. V. Metcalfe* T. Sritharan ${ }^{\ddagger}$
}

(Received 8 November, 2005; revised 11 July, 2006)

\begin{abstract}
As the centrepiece of Canberra, Lake Burley Griffin provides the setting for buildings of national importance and a venue for aquatic recreation while, as part of the Molonglo River, the lake has a role in the ecological processes of its broader setting. For the purposes of recreation and landscape a constant water level is preferred: the management plan requires the lake to be maintained at a prescribed normal level. In years of low rainfall this requirement could conflict with the water demands of other users. Episodes of high rainfall may also require compromise between competing objectives. For example,
\end{abstract}

*School of Mathematical Sciences, University of Adelaide, Adelaide, Australia. mailto:roger. webby@adelaide.edu.au

$\dagger$ Centre for Industrial and Applied Mathematics, University of South Australia, Adelaide, Australia

${ }_{\ddagger}^{\ddagger}$ National Capital Authority, Canberra, Australia

See http://anziamj.austms.org.au/V47EMAC2005/Webby for this article, C Austral. Mathematical Soc. 2006. Published July 27, 2006. ISSN 1446-8735 
drawdown of lake levels for flood mitigation could impact on the lake's recreational and amenity values and the spill may not be a good use of water. Conditional Value at Risk, a risk measure developed by the financial industry for portfolio management, is defined as the expected loss given that some loss threshold is exceeded. Here, Conditional Value at Risk is applied as decision support for strategic planning and day-to-day operational problems in the hydraulic management of Lake Burley Griffin.

\section{Contents}

1 Introduction

2 Model definition

2.1 Valuation of water height . . . . . . . . . . . .

2.2 Calculation of VaR and CVaR . . . . . . . . . . .

3 Simulation results

3.1 Decide minimal water level for release of environmental flows C130

3.2 Optimal drawdown for flood mitigation . . . . . . . . .

4 Conclusion

References

\section{Abbreviations}

AHD $=$ Australian Height Datum $\quad$ ENV $=$ Expected Net Value

AIS = Australian Institute of Sport $\mathrm{Ml}=$ Mega-litres

$\mathrm{CVaR}=$ Conditional Value at Risk $\quad \mathrm{VaR}=$ Value at Risk 


\section{Introduction}

Lake Burley Griffin is an integral part of Walter Burley Griffin's design for Canberra. The lake is the setting for, among other buildings of national importance, Parliament House, the National Gallery of Australia and the National Museum of Australia. The lake and surrounding parklands are used for recreation by the public and by the AIs rowing program. Lake Burley Griffin is also part of the Molonglo River, a tributary of the MurrayDarling system. The lake links its immediate urban surroundings with lesserdeveloped areas upstream and downstream. The water height of the lake can be manipulated to provide a retention basin to mitigate flood impact, and/or to deliver environmental flows to the downstream reaches of the Molonglo River. The lake management plan requires the lake to be maintained at a normal level of AHD 555.93 metres. These are conflicting demands on the water height of the lake.

Lake Burley Griffin covers an area of 664 hectare. With water height at the prescribed normal (or reference) level, the lake has a volume of $33,700 \mathrm{Ml}$, mean depth of $4 \mathrm{~m}$ and maximum depth of approximately $18 \mathrm{~m}$. Water height is managed by the gates of Scrivener Dam at the western end of the lake. The lake is managed by the National Capital Authority, Canberra. The managers of Lake Burley Griffin and its surroundings intend to release environmental flows for the maintenance of the riverine ecosystem of the lower Molonglo River. Demand for environmental flows is a situation faced by many managers of water bodies in Australia. Placing a value on alternative uses enables a calculation of the trade-off between retaining and releasing the water.

There is near real-time monitoring of stream flow in Lake Burley Griffin's catchment (for a description of this system, see [2]) so that managers can anticipate the magnitude of an inflow to the lake resulting from rainfall events in the catchment. The lake level may be drawn down at the dam prior to receiving inflow. This allows the volume of a flood pulse heading downstream to be spread over a longer time, or poor quality runoff to be held (and 
subsequently ameliorated) in the lake. Again, a trade-off occurs between releasing and retaining the water.

Value at Risk is a risk measure developed in the financial services arena. It is defined as the maximum loss expected to be incurred over a given time horizon at a specified level of probability. VaR does not indicate how much worse than the calculated var value the loss might be. Conditional Value at Risk does take into account any extremely large losses which may occur, albeit with low probability, in the tail of the distribution. CVar is defined as the expected loss given that the loss is greater than or equal to the var value. VaR and CVaR have been demonstrated in agricultural enterprises [6] and in electricity generation in deregulated markets [3] as risk measures suitable for developing rules for optimal allocation of resources. The sensitivity of CVaR to large losses occurring in the tail of a loss distribution means that it may be used by a risk-averse manager.

Harman and Stewardson [4] developed dam operating rules for the optimal release of water to meet environmental flow requirements. They assumed that releases would be made to attempt to meet environmental flow targets. Their objective criterion for choosing between rules was the level of compliance with the targets at downstream monitoring points against the volume of water released. Jenkins et al. [5] developed monthly demand functions for urban water use in California. Losses were assigned where supply fell short of demand. The authors costed environmental flows as the opportunity cost of not meeting urban demand. Their model was developed to evaluate the performance of infrastructure and management alternatives against their potential losses.

Here we find the optimal level of drawdown of water height for environmental flow releases and/or flood mitigation to give the minimum loss in the lake's values. Section 2.1 describes our water balance model including the valuations of water height that generate loss, and Section 2.2 describes the risk measures used. Results from simulations are presented and discussed in Section 3. 


\section{Model definition}

\subsection{Valuation of water height}

Loss of abstraction earnings Water is regularly abstracted or withdrawn from the lake and sold to irrigators of surrounding grassed areas and gardens. For the model, abstracted water is valued at $\$ 0.20$ per kilolitre. A daily maximum of $0.002 \mathrm{~m}$ (equivalent to a volume of $14 \mathrm{Ml}$ ) of lake water level may be abstracted when water height is within $0.2 \mathrm{~m}$ of its reference level. Below this, we permit abstractions on a stepped scale, following the guidelines [1], and extending them to specify further staged reductions in abstraction for lake levels more than $0.6 \mathrm{~m}$ below reference level. No abstraction is permitted on wet days. Loss of abstraction earnings or potential sales is defined to be the proportion of potential daily earnings foregone due to drawdown of lake level below the first step. For what follows, we set $h$ as a variable representing water height and $r$ as a constant representing the reference level, (thus $(r-0.5)$ is half a metre below reference level or AHD 555.43). Then, and see Figure 1, the loss of abstraction earnings is

$$
\operatorname{loss}_{E}= \begin{cases}0, & \text { for }(r-0.2) \leq h<r \\ 420, & \text { for }(r-0.4) \leq h<(r-0.2), \\ 840, & \text { for }(r-0.6) \leq h<(r-0.4), \\ 1260, & \text { for }(r-0.8) \leq h<(r-0.6), \\ 2800, & \text { for } h<(r-0.8) .\end{cases}
$$

Loss of amenity Amenity loss corresponds to the decline in the scenic value of the lake as its water level falls and the cost of infrastructure replacement if lake levels are exceedingly low. The model has loss as piecewise linear with retreating lake level (see Figure 1). As the lake level recedes past $0.4 \mathrm{~m}$ below reference level, the scenic value of the lake may become seriously 

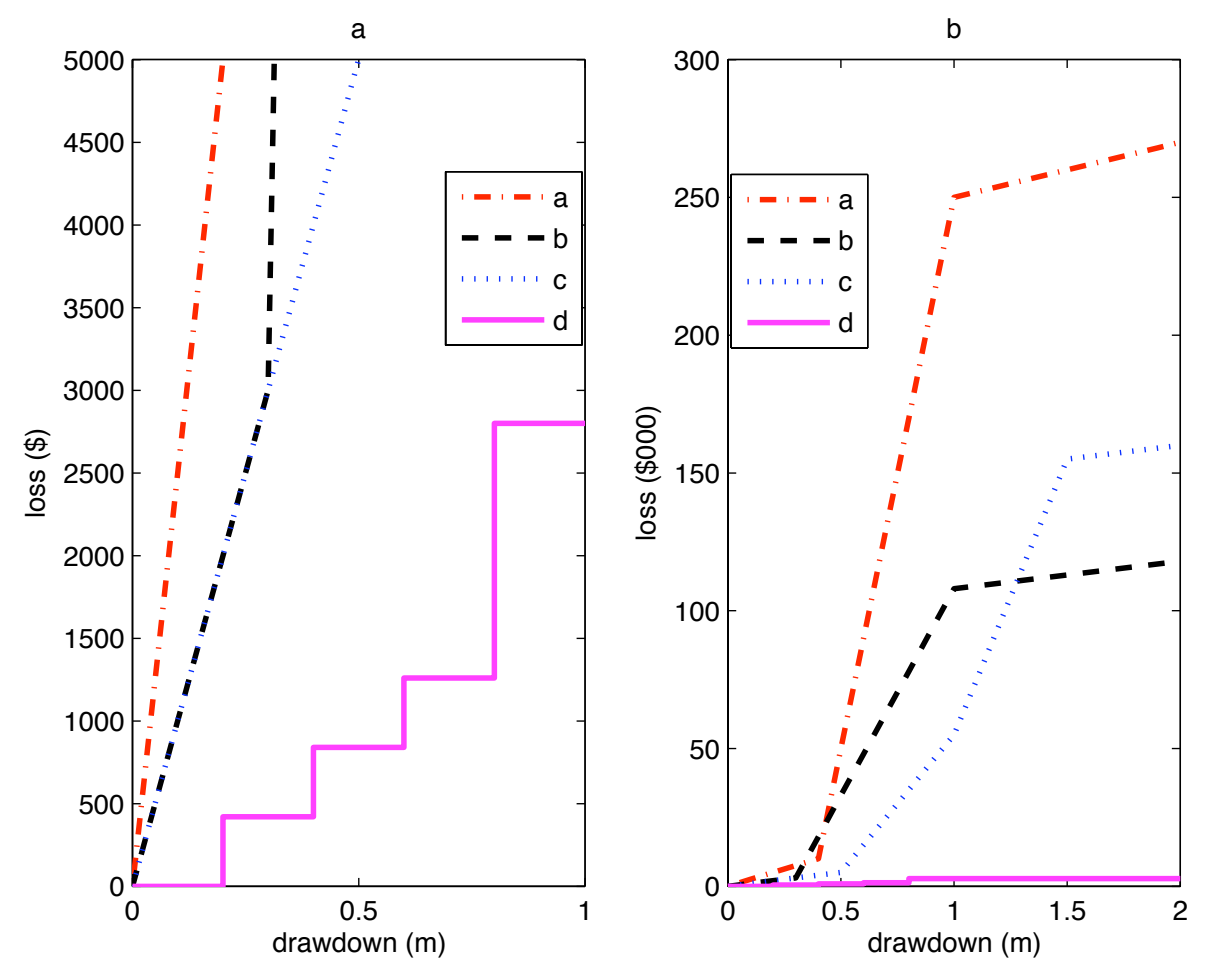

FIGURE 1: daily loss against drawdown for a) amenity, b) recreation, c) wetland values and d) potential sales, showing different scales for drawdown: (a) 0-1 m and (b) 0-2 m. Loss in \$ (a) and \$thousands (b). 
degraded (due to exposed foreshore areas) and loss of hydraulic pressure may cause the collapse of rock walls edging the lake. Further reductions in lake level may see saline groundwater seepage into the lake basin and the uncovering of hazardous objects on the lake floor. The chance of injury or mortality of humans produces higher values for loss at lower water levels. The loss of amenity is

$$
\operatorname{loss}_{A}= \begin{cases}25000 \times(r-h), & \text { for }(r-0.4) \leq h<r, \\ 10000+400000 \times((r-0.4)-h), & \text { for }(r-1) \leq h<(r-0.4), \\ 250000+20000 \times((r-1)-h), & \text { for }(r-2) \leq h<(r-1)\end{cases}
$$

Loss of recreational amenity Recreation loss is based on a contingency valuation approach. For this study, we estimate that $10 \%$ of local people use the lake on a given summer day. The AIS rowing program is based in Canberra and uses the waters for training. There are 3,000 boats moored/ stored on the lake and nearby areas. 60 to 65 regattas take place there each year. Such organised activities (or their loss) would have associated commercial impact for local business. The model has loss as piecewise linear with declining lake level (see Figure 1):

$$
\operatorname{loss}_{R}= \begin{cases}10000 \times(r-h), & \text { for }(r-0.3) \leq h<r, \\ 3000+150000 \times((r-0.3)-h), & \text { for }(r-1) \leq h<(r-0.3), \\ 108000+10000 \times((r-1)-h), & \text { for }(r-2) \leq h<(r-1)\end{cases}
$$

Loss of wetlands value A wetland is comprised of water, plants and organisms, interacting to create a whole system. As water levels decline, degradation of wetland values may be seen in the death of vegetation, water quality problems and in lower relative humidity near the lake. The model 
has wetland loss as piecewise linear against water height (see Figure 1):

$$
\operatorname{loss}_{W}= \begin{cases}10000 \times(r-h), & \text { for }(r-0.5) \leq h<r, \\ 5000+100000 \times((r-0.5)-h), & \text { for }(r-1) \leq h<(r-0.5), \\ 55000+200000 \times((r-1)-h), & \text { for }(r-1.5) \leq h<(r-1), \\ 155000+10000 \times((r-1.5)-h), & \text { for }(r-2) \leq h<(r-1.5) .\end{cases}
$$

As Figure 1(a) shows, loss of abstraction earnings is dominated by losses in amenity, recreation and wetlands' values, and excluding abstraction earnings from the model does not change the results found here.

Loss due to flood Inflow events are modelled with lake level possibly rising above the reference level. The excess water height (converted to a spill volume) is passed over Scrivener Dam and a loss due to flood damage calculated according to Equation (5) (and see Figure 2). Loss due to flood rises slowly at first, representing temporary road closures and minor damage. The steepening curve reflects the potential for larger floods to destroy infrastructure, put people at risk, and spread beyond the river channel. The greater scale of flood loss in the model is intended to capture the capacity of sudden, high-intensity flood events to cause proportionate damage. The equation for flood loss, initially cubic then linear against spill, is (where $s$ is spill in $\mathrm{Ml}$ ),

$$
\operatorname{loss}_{F}= \begin{cases}(s / 35)^{3}, & \text { if } 0 \leq s<12000 \\ 40303207+12595 \times(s-12000), & \text { if } 12000 \leq s<15000\end{cases}
$$

Rainfall model Rainfall and demands are modelled for the month of February. It is interesting to consider February as, during that month, the lake may experience short periods of high inflows and long periods of low inflows, while total demand for water in February is above average. 


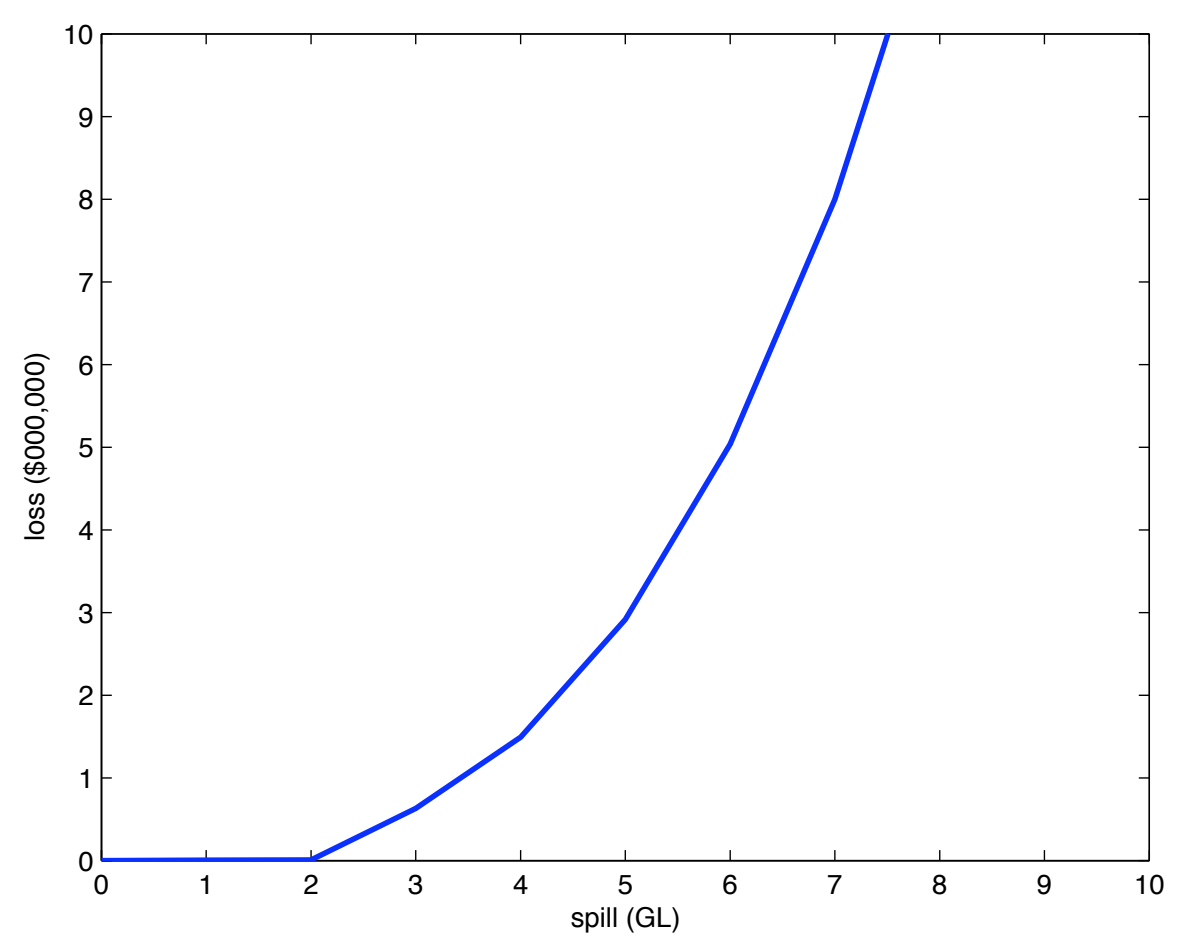

Figure 2: Daily loss from downstream flooding against spill; spill in gigalitres, loss in \$millions. A spill of $5 \mathrm{Gl}$ is equivalent to a drawdown of $0.6 \mathrm{~m}$. 
The rainfall model was developed from daily February rainfall data from a 129 year record. For a given day, rainfall may be zero or strictly positive, according to the proportion of wet and dry (0.7818) days in the record. From that random starting point, a sequence of wet and dry days is generated by a two state Markov chain whose parameters were empirically estimated. The wet to dry and dry to wet transition probabilities are 0.4214 and 0.1357 , respectively. For wet days, rainfall (in $\mathrm{mm}$ ) is represented by a non-negative random variable, generated by sampling from a truncated Gamma $(0.68,13.35)$ probability distribution. The Gamma probability density function is

$$
p(y, \alpha, \beta)=\frac{1}{\beta^{\alpha} \Gamma(\alpha)} y^{\alpha-1} \exp ^{-y / \beta} \quad \text { for } y, \alpha, \beta>0 .
$$

The distribution was fitted to the above-mentioned data (see Figure 3). We arbitrarily truncate the maximum daily rainfall that could be generated by the model at $134 \mathrm{~mm}$, approximately twice the historical maximum.

Water balance equation The water height of the lake for a given day is the sum of the previous day's water level plus stochastic and deterministic inflows, minus evaporation loss, demand and any spill or releases for environmental flow. Deterministic inflow is from an upstream sewage treatment plant and evaporation is treated as a constant rate $(7.3 \mathrm{~mm}$ per day) for dry days. We ignore groundwater inflows and seepage losses as little information on these is available, and they are thought to not make a major contribution to the water balance. Let $h(t)$ be height on day $t, i(t)$ be inflow, $d(h(t))$ be the abstraction amount, $e$ be the evaporation rate and $f(h(t))$ be a release made for environmental flow. The water balance equation is

$$
\begin{aligned}
h(t)=h(t-1)+k i(t)-k s(h(t))-k d(h(t)) I_{A}(t)-e I_{A}(t) \\
-k f(h(t)) \operatorname{int}\left\{1-\frac{t}{7}+\operatorname{int}\left(\frac{t}{7}\right)\right\}-m(h(t)) I_{B}(t) .
\end{aligned}
$$

We set deterministic inflow at $10 \mathrm{Ml}$ per day, stochastic inflow is generated by the rainfall model with rainfall (in $\mathrm{mm}$ ) multiplied by 111.3 to obtain 


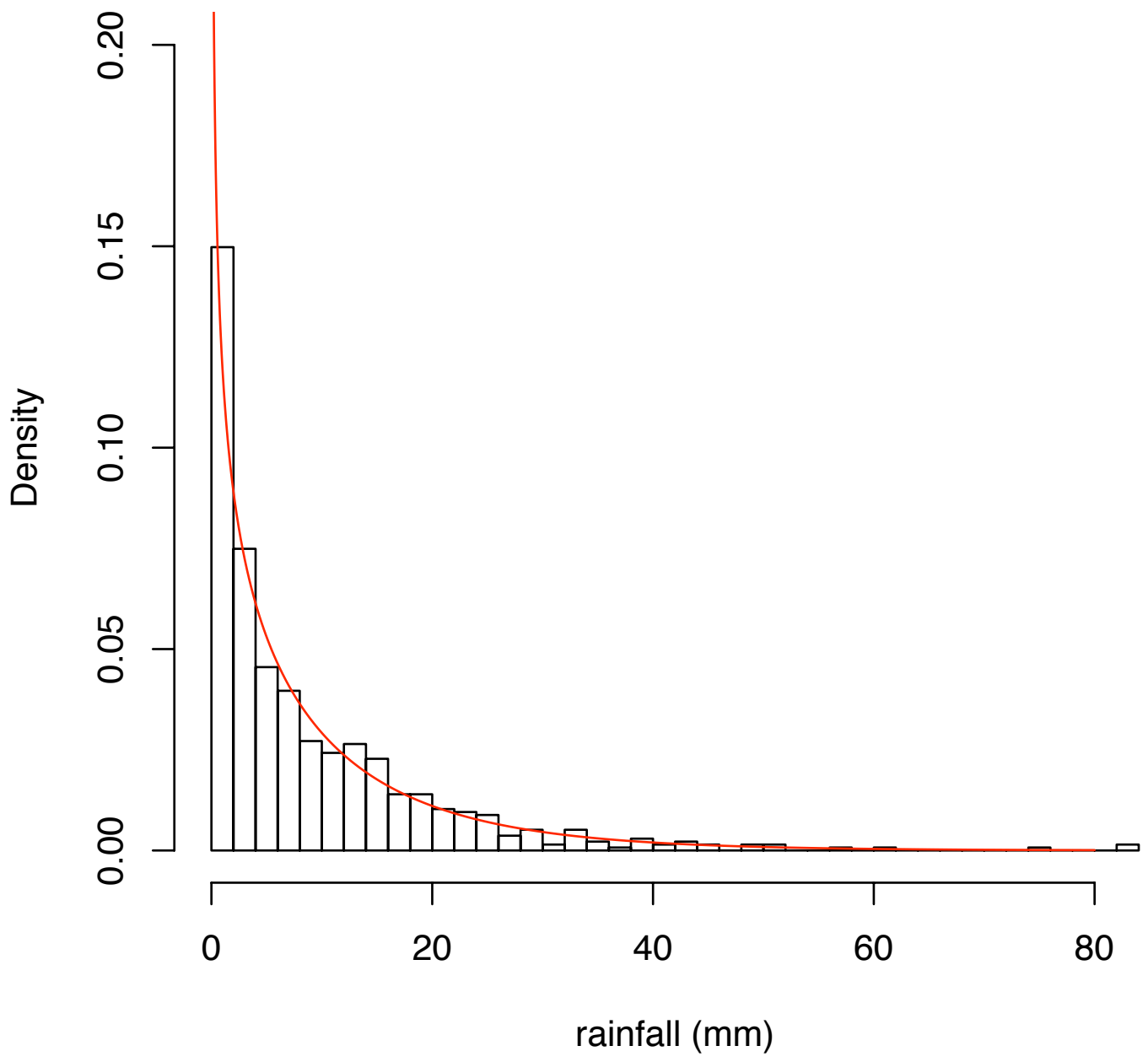

FiguRE 3: February rainfall and fitted density. 
inflow to the lake (in $\mathrm{Ml}$ ). Dividing volume by area gives a value for height. $k$ is a constant $\left(1.212 \times 10^{-4}\right)$ converting volume to height. If inflow takes the lake level above the reference level, the excess is spilled, thus

$$
s(h(t))=\max (0, h(t)-r) 8333 .
$$

Abstraction amounts (in Ml) in the model are made on a stepped scale, occurring only on dry days as

$$
d= \begin{cases}14, & \text { for }(r-0.2) \leq h<r \\ 11.9, & \text { for }(r-0.4) \leq h<(r-0.2) \\ 9.8, & \text { for }(r-0.6) \leq h<(r-0.4) \\ 6.3, & \text { for }(r-0.8) \leq h<(r-0.6) \\ 0, & \text { for } h<(r-0.8)\end{cases}
$$

$I_{A}(t)$ is an indicator function where $A$ is the set of dry days and so

$$
I_{A}(t)= \begin{cases}1, & \text { if } t \in A, \\ 0, & \text { if } t \notin A\end{cases}
$$

The term int $\left\{1-\frac{t}{7}+\operatorname{int}\left(\frac{t}{7}\right)\right\}$ determines whether $t$ occurs at the end of a 7 day simulation period. It takes a value of 1 on the last day of the period and 0 otherwise. $f(h(t))$ is the amount of any release made to meet a weekly environmental flow target (described in Section 3.1). $m(h(t))$ is the drawdown in lake level made for flood mitigation (described in Section 3.2). $I_{B}(t)$ is an indicator function where $B$ is the set of wet days with predicted rainfall greater than $10 \mathrm{~mm}$ :

$$
I_{B}(t)= \begin{cases}1, & \text { if } t \in B, \\ 0, & \text { if } t \notin B\end{cases}
$$




\subsection{Calculation of VaR and CVaR}

Let $x \in X \subset \mathbb{R}^{n}$ be a decision vector, and $y \in Y \subset \mathbb{R}^{m}$ be a vector representing the values of a contingent variable influencing the loss. Let $z=f(x, y)$ be a function that describes the loss generated by $x$ and $y$. VaR and CVaR are associated with a particular confidence level, $\alpha \in(0,1)$. The $\operatorname{VaR}_{\alpha}$ of the loss associated with a decision $x$ is defined as

$$
\operatorname{VaR}_{\alpha}(x)=\min \{z \mid G(x, z) \geq \alpha\},
$$

where $G(x, z)$ is the cumulative density function for loss associated with decision $x$. The $\mathrm{CVaR}_{\alpha}$ of the loss associated with a decision $x$ is defined [7] as

$$
\operatorname{CVaR}_{\alpha}(x)=\mathrm{E}\{z \mid G(x, z) \geq \alpha\},
$$

where E denotes the expectation operator. Figure 4 illustrates VaR and CVaR for an empirical distribution of loss.

Generating the loss distribution Our decision variable is drawdown of water height below the reference level and we consider a range from 0 to $1 \mathrm{~m}$ in $0.05 \mathrm{~m}$ increments. Loss is calculated on a daily basis in dollar units using Equations (1)-(5). Daily loss is summed to obtain a monthly total and computer simulation of 7000 months generates an empirical monthly loss distribution, $G(x, z)$. Such a distribution is found for a range of values of the decision variable, $x$. We set $\alpha=0.90$. We define ENV to be the mean value of the monthly loss distribution. In this paper VaR and ENV are found as the appropriate quantiles of the loss distribution. CVaR is found by numerical calculation according to the definition in Equation (12).

We are able to generate separate distributions for loss due to low lake levels (comprising loss of abstraction, amenity, recreation and wetlands values) and one for high lake levels (loss due to flood). These combine to give the total loss distribution. Risk measures are calculated for each of these distributions. We define total Var (TVar) as the VaR value calculated from the 


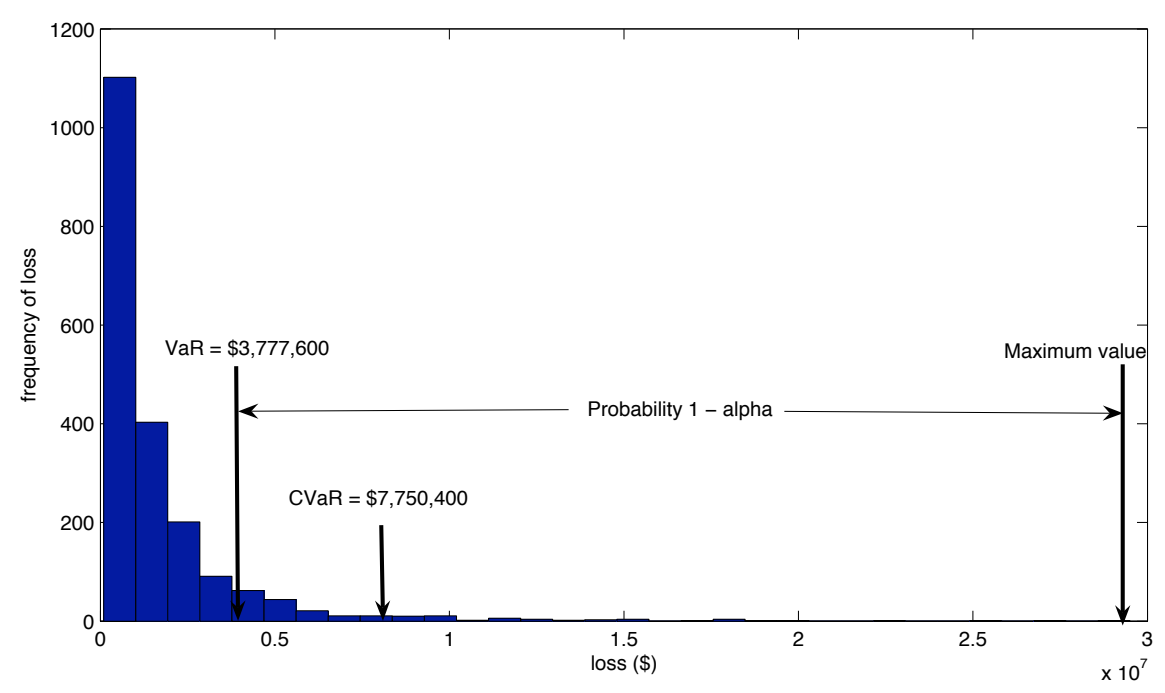

Figure 4: An example of the loss distributions simulated in Section 3.1 with VaR and CVar indicated. 
total loss distribution. We define lower CVaR (LCVaR), upper CVaR (UCVaR) and total CVar (TCVaR) as the CVaR value calculated from the distributions for loss due to low lake levels, loss due to high lake levels and the combined loss distribution, respectively. These values are not generally additive, and TCVaR can not exceed the sum of LCVaR and UCVaR. The minimum value for TCVaR (across the range of values of the decision variable) does not generally coincide with the minimum value for LCVaR or that for UCVaR. In managing water height primarily to minimise the risk of large losses due to flooding, for example, it may be useful to minimise UCVaR against drawdown of water height in order to determine optimal management rules.

\section{Simulation results}

\subsection{Decide minimal water level for release of environmental flows}

We set a target for weekly environmental baseflow. Inflows from rainfall contribute toward meeting the target (or may exceed it). Releases from the lake could be made to supplement rainfall and make up any shortfall in environmental flow. We include a penalty, proportional to any shortfall, in the model and find the minimum value of TCVaR against our decision variable. Thus, a minimum water height could be specified beyond which a release for environmental flows is not made. Letting $c$ be the penalty amount, $g$ be the environmental flow target and $u$ be accumulated spill over the period, our penalty function is

$$
c=100000 \times \frac{(g-u)}{g} .
$$

The model tracks spill over a 7 day period and makes supplementary releases to meet the environmental flow target if there is sufficient water height in 

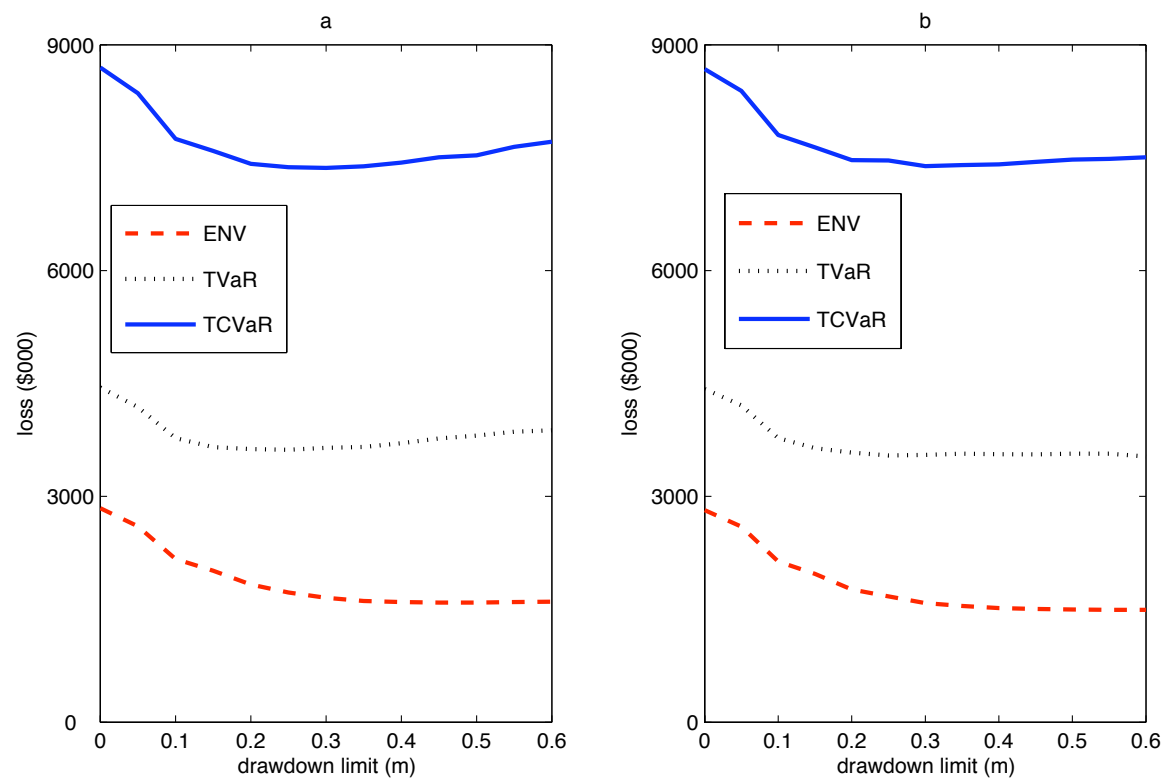

FiguRE 5: ENV, TVaR and TCVaR values for drawdown limits between 0 and $0.6 \mathrm{~m}$ below reference level and requirement for weekly environmental flow of (a) $500 \mathrm{Ml}$, (b) $400 \mathrm{Ml}$. In (a) ENV declines for any drawdown limit; TVaR and TCVar have a minimum at $0.3 \mathrm{~m}$. In (b) the optimum is also at $0.3 \mathrm{~m}$ but is less evident.

the lake. Thus any potential release is

$$
f(h)=\max (0, g-u) .
$$

Figure 5(a) and 5(b) show values of the risk measures for minimum weekly environmental flows of $500 \mathrm{Ml}$ and $400 \mathrm{Ml}$ respectively, interpolating between the calculated values. The optimal drawdown limit is approximately 0.3 metre for both the $500 \mathrm{Ml}$ and $400 \mathrm{Ml}$ weekly environmental flows, suggesting that supplementary releases should not be made when water height is below $0.3 \mathrm{~m}$ below reference level. Note that the value of ENV is always below 


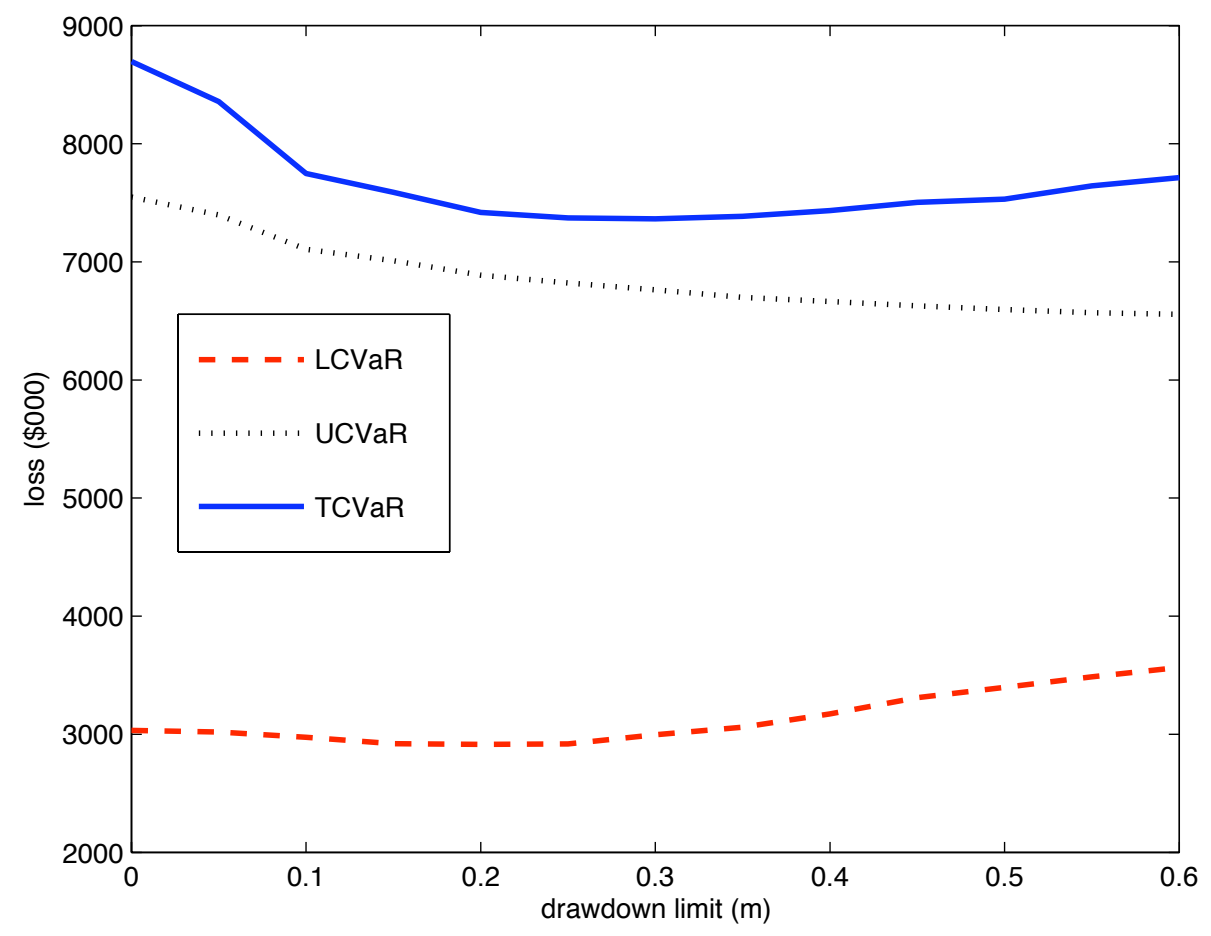

FiguRE 6: LCVaR, UCVaR and TCVaR values against drawdown limit, and for a weekly environmental flow of $500 \mathrm{Ml}$. LCVaR has a minimum at a drawdown of $0.2 \mathrm{~m}$, UCVaR declines in value for all drawdown, TCVaR is a weighted average of the two and has a minimum at approximately $0.3 \mathrm{~m}$. 
that of the two risk measures and that VaR is similarly always below CVaR. CVar is more sensitive to large losses in the tail than VaR and so is a better indicator of risk if managers wish to avoid such loss.

Figure 6 shows that LCVaR attains a minimum at approximately $0.23 \mathrm{~m}$ and TCVaR at approximately $0.3 \mathrm{~m}$. If it was decided that achieving environmental flow goals was of overriding importance and we minimise LCVaR, we obtain a value of $\$ 2915$, compared to a value of $\$ 7365$ for TCVaR. Note that UCVaR is monotone on this interval, indicating that flood damage is reduced if lake level is drawn down to intercept large flows.

We noticed a trend for the shape of the risk measures to be monotonic. To obtain minima, the problems had to be balanced between the two competing objectives. When more weight is placed on the value of having the lake at its reference level, model output indicates that it should never be drawn down. If the weight is on environmental flow goals, the model indicates that managers should always make releases. Thus the model is sensitive to the assumptions made in the loss schedules in Section 2.1.

\subsection{Optimal drawdown for flood mitigation}

Lake Burley Griffin has a limited capacity to store runoff from rainfall events. If early drawdown of water is made, inflow following rainfall can be anticipated to refill the lake (with the benefits mentioned in Section 1). However, the conflicting demands of flood mitigation, maintenance of lake reference level and river health issues suggest we test for an optimal drawdown value to minimise loss from the competing objectives. If we had reliable forecasts that rain would exceed $10 \mathrm{~mm}$ in a day but no further information, optimum draw down is $0.2 \mathrm{~m}$ below reference level. (See Figure 7). The losses in Figure 7 all assume that a drawdown may be made, provided water height is no lower than $0.3 \mathrm{~m}$ below reference level, to meet a weekly environmental flow target of $500 \mathrm{Ml}$. It is possible that optimum drawdown for flood mitiga- 


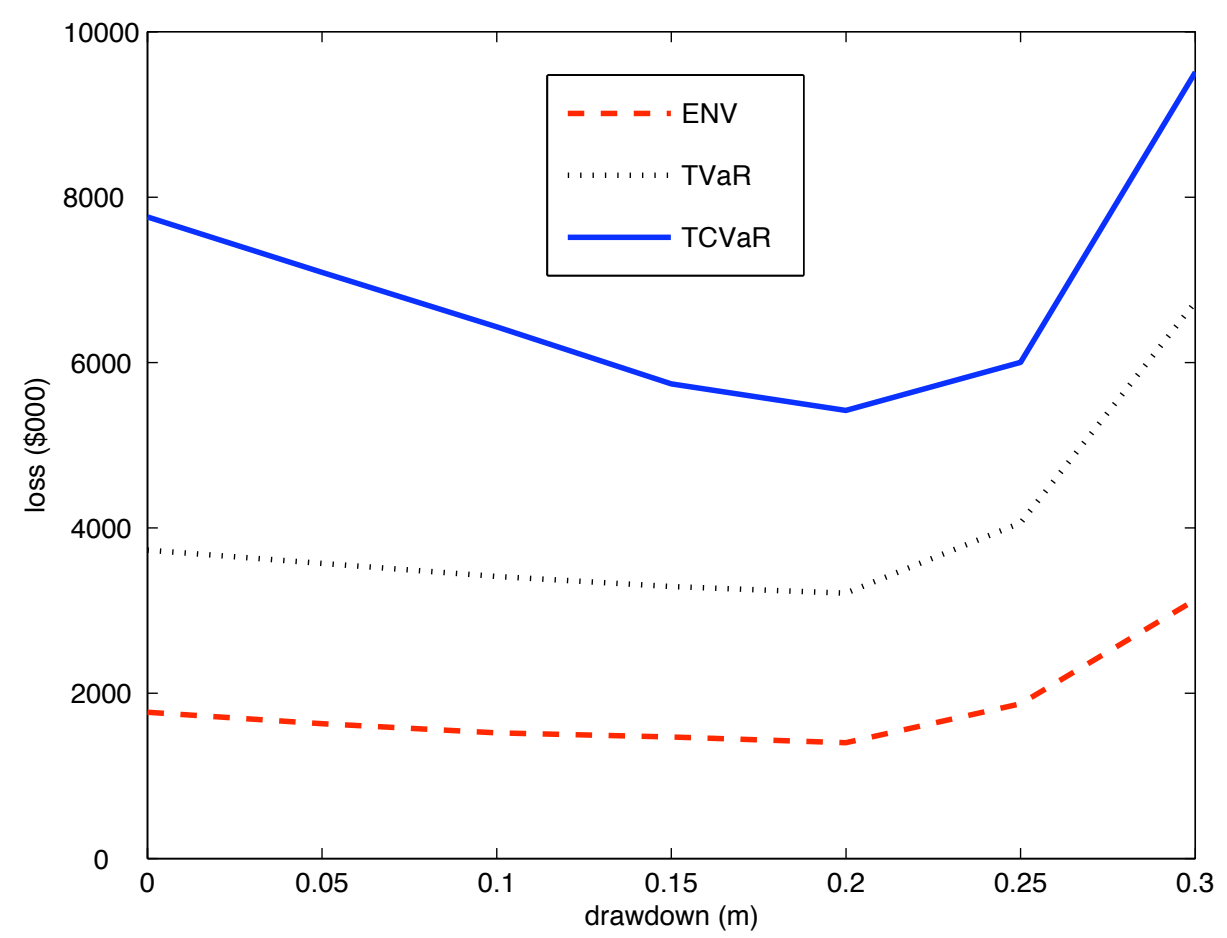

FiguRE 7: Risk measure values for drawdown amounts between 0 and $0.3 \mathrm{~m}$ of water height when rainfall greater than $10 \mathrm{~mm}$ is expected. ENV, TVaR and TCVaR are minimised at a drawdown of $0.2 \mathrm{~m}$. 
tion may depend on the allowable drawdown for environmental flows. This requires further investigation.

\section{Conclusion}

The model described in this paper was created to assess and demonstrate the potential of using CVaR as a tool in developing rules for the optimal management of water height of a lake. Parameter fitting required the setting of values against the degradation of Lake Burley Griffin's attributes. The model found an optimal drawdown of water height for dam releases to meet environmental flow targets. Furthermore, it identified an optimum drawdown before significant rainfall events to minimise flood losses. We note that, in the latter scenario, current management strategy is to draw down the lake in these circumstances.

The model is based on Lake Burley Griffin but the methodology could be applied to similar issues at other reservoirs. To do so requires the assigning of monetary values to the water in the reservoir under the range of management options being considered. The relative magnitude placed on the values of competing objectives may be important in model output. An extension of the present model is sensitivity testing of our loss distribution parameters.

The values of model parameters and loss distributions assumed here are for model calculations only. While values for parameters are chosen to represent the real situation, they are assumed values. They should not be taken as real values for any other purposes.

Acknowledgments: We thank the Australian Research Council for supporting this research under grant number DP0559399. 


\section{References}

[1] National Capital Authority. Lake Burley Griffin Abstraction Plan 2005. National Capital Authority, 2005.

http://www nationalcapital.gov. au/corporate/publications/. C120

[2] R. Ayre, W. Shallcross, and T. Sritharan. Flood management of Lake Burley Griffin. In B. C. Phillips, editor, Proceedings of the 29th Hydrology and Water Resources Symposium. Institute of Engineers Australia, 2005. C118

[3] R. Dahlgren, C. Liu, and J. Lawarrée. Risk assessment in energy trading. IEEE Transactions On Power Systems, 18:503-511, 2003. http://dx.doi.org/10.1109/TPWRS.2003.810685 C119

[4] C. Harman and M. Stewardson. Optimising dam release rules to meet environmental flow targets. River Research And Applications, 21:113-129, 2005. http://dx.doi.org/10.1002/rra.836 C119

[5] M. Jenkins, J. Lund, and R. Howitt. Using economic loss functions to value urban water scarcity in California. Journal of the American Water Works Association, 95:58-70, 2003. C119

[6] L. Pruzzo, R. Cantet, and C. Fioretti. Risk-adjusted expected return for selection decisions. Journal of Animal Science, 81:2984-2988, 2003. http://jas.fass.org/cgi/content/full/81/12/2984 C119

[7] R. Rockafellar and S. Uryasev. Conditional value-at-risk for general loss distributions. Journal of Banking and Finance, 26:1443-1471, 2002. http://dx.doi.org/10.1016/S0378-4266(02)00271-6 C128 